\title{
CEREBELLAR ABSCESS BY Gemella morbillorum IN A PATIENT WITH INTER-ATRIAL COMMUNICATION
}

\author{
Armando Lopes', Rui Providencia², Rui Pedro Pais', \\ Maria João Frade ${ }^{4}$, Feres Chaddad Neto ${ }^{5}$, Evandro de Oliveira ${ }^{6}$
}

\begin{abstract}
Gemella morbillorum, a commensal of the oropharynx, upper respiratory, urogenital and gastrointestinal tract is rarely associated with infections in humans. However, an increasing number of infectious processes in different locations have been reported. Cerebral abscesses caused by these bacteria are extremely uncommon with only four cases previously described in the literature. We present the case of a cerebellar abscess by Gemella morbillorum in a 50 years-old man with inter-atrial communication dealt by surgical excision and antimicrobial therapy.
\end{abstract}

KEY WORDS: cerebellar abscess, inter-atrial communication, Gemella.

\begin{abstract}
Abscesso cerebelar por Gemella morbillorum em paciente com comunicação inter-atrial
RESUMO - Gemella morbillorum, uma bactéria comensal da orofaringe, vias aéreas superiores e aparelhos urogenital e gastrointestinal, raramente causa infecções em humanos. No entanto, um crescente número de processos infeciosos em diferentes localizações tem sido referido. Abcessos cerebrais provocados por esta bactéria são extremamente raros, encontrando-se apenas quatro casos previamente descritos na literatura. Apresentamos o caso de um abscesso cerebelar por Gemella morbillorum em um homem de 50 anos com comunicação inter-atrial, tratado por excisão cirúrgica e terapêutica antimicrobiana.
\end{abstract}

PALAVRAS-CHAVE: abscesso cerebelar, comunicação inter-atrial, Gemella.

Cerebral abscesses are usually associated with conditions like pulmonary abnormalities, congenital cyanotic heart disease, bacterial endocarditis, penetrating head trauma and AIDS. The source of cerebral abscess is either hematogenous (congenital cyanotic heart disease, lung abscess, empyema, pulmonary arterio-venous fistulas, bacterial endocarditis and gastro-intestinal infections) or contiguous spread from sinuses or dental region diseases.

Histological classification of abscesses enclosures four stages (early cerebritis, late cerebritis, early capsule and late capsule), progressing for at least two weeks. Clinical features are unspecific and are related to the abscess location and surrounding edema. Most of the symptoms are due to raised intracranial pressure. Motor deficits and seizures are also common. Blood work with peripheral cell blood count, erythrocyte sedimentation rate and $\mathrm{C}$ - reactive protein may reveal normal or unspecific results. Blood cultures are usually negative.
Lumbar puncture should be avoided due to the risk involved and the low yield of useful information obtained.

Computerized tomography and magnetic resonance imaging are irreplaceable in the characterization of the lesion, but the radiological findings vary in different stages of abscess formation. Surgical drainage (open or needle) or excision plus antimicrobial therapy is the treatment of choice. Medical therapy alone may be used in early abscess and in patients with multiple small abscesses or those located in critical areas (brain stem, internal capsule...).

Initial combination of antimicrobial drugs should include vancomycin, third generation cephalosporin and metronidazole or cloranphenicol. When in vitro sensitivities become available appropriate therapy changes must be made. Antimicrobial therapy is discontinued after 6-8 weeks. The use of steroids should be reserved for those cases presenting with significant mass effect and clinical related deterioration

\footnotetext{
${ }^{1}$ Médico Residente do Centro de Neurocirurgia de Coimbra, Centro Hospitalar de Coimbra, Portugal (CHC); ${ }^{2}$ Médico Residente do Serviço de Cardiologia, $\mathrm{CHC}$; ${ }^{3}$ Neurorradiologista do Serviço de Neurorradiologia, $\mathrm{CHC}$; ${ }^{4}$ Neurocirurgiã do Centro de Neurocirurgia de Coimbra, CHC; ${ }^{5}$ Neurocirurgião do Instituto de Ciências Neurológicas, São Paulo, Brasil (ICNE), Neurocirurgião-Assistente da Disciplina de Neurocirurgia do Departamento de Neurologia da Universidade de Campinas, Campinas SP, Brasil (UNICAMP); ${ }^{6}$ Diretor do ICNE, Professor e Chefe da Disciplina de Neurocirurgia da Faculdade de Ciências Médicas da UNICAMP.
}

Received 14 March 2007, received in final form 26 June 2007. Accepted 20 August 2007.

Dr. Feres Chaddad Neto - Praça Amadeu Amaral 27 / $5^{\circ}$ andar - 01327-010 São Paulo SP - Brasil. E-mail: fereschaddad@hotmail.com 
because they may reduce penetration of antibiotics into the abscess.

Anticonvulsants are usually recommended.

Although mortality has been significantly reduced with improvement in antibiotics, surgery and CT diagnosis and follow-up, morbidity is still high, with neurological deficits and seizures being the most common complications.

\section{CASE}

A 50 years-old man, transferred from another institution, presenting with headache, vomiting, dizziness and gait ataxia in association with fever for the past fifteen days, after a dental procedure. He had no motor deficits but there was uncoordination of motion on the right side.

Twenty years earlier he had been diagnosed a congenital cardiac malformation for which he denied surgery. He had Class II New York Heart Association classification for heart failure symptoms. Enlargement of the right cardiac chambers, paradoxal movements of the inter-ventricular septum and flow through an inter-auricular septum defect were seen in previous trans-thoracic echocardiograms.

Blood sampling revealed leucocytosis (12000 cells $/ \mathrm{mm}^{3}$ ) and elevation of C-reactive protein.

Both computerized tomography (Fig 1) and magnetic resonance imaging (Figs 2 and 3 ) showed a cystic lesion with a peripheral rim of contrast enhancement and involving edema, located in the right medial cerebellar hemisphere and vermis.

Intravenous therapy with ceftriaxone, vancomycin and metronidazole was empirically initiated.

A short course of steroids was used to reduce the mass effect from the lesion.

Pre-operative electrocardiogram was consistent with a right blockage pattern of His bundle and right auricle anomaly. Blood cultures were negative.

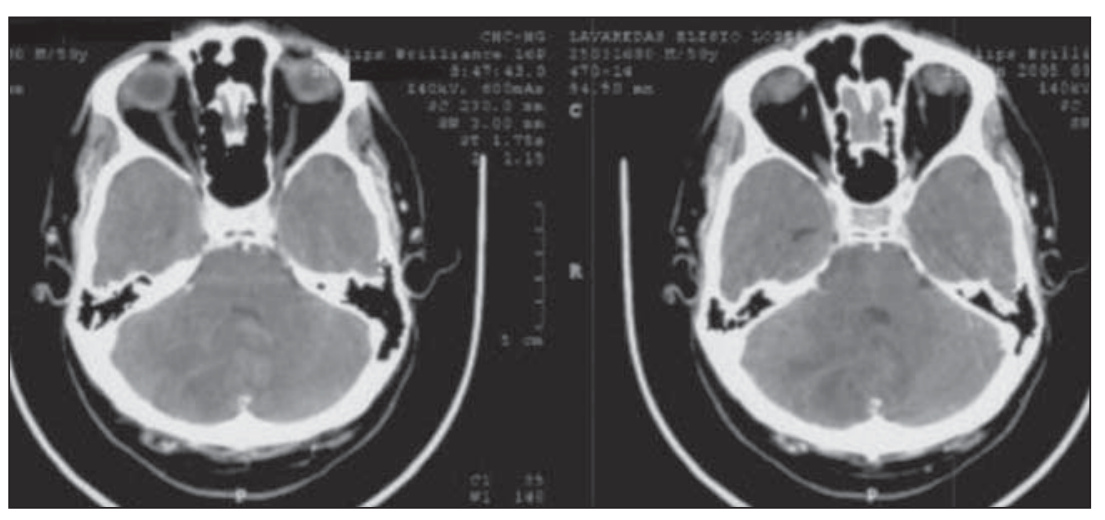

Fig 1. CT with IV contrast revealing vermian and right hemispheric lesion, with heterogeneous enhancement and surrounding hipodensity.

Fig 2. Sagital, coronal and axial TIWI after gadolinium, with better characterization of a cystic lesion with a peripheral rim of contrast enhancement affecting the vermis and the medial right cerebellar hemisphere.

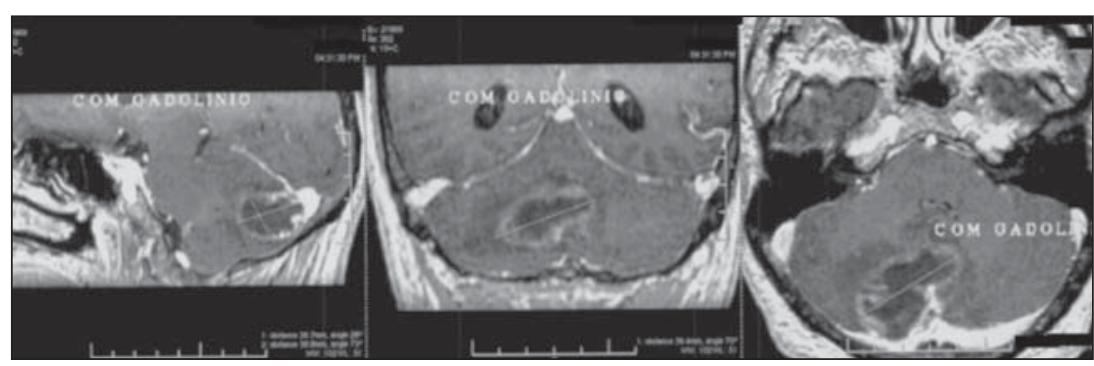

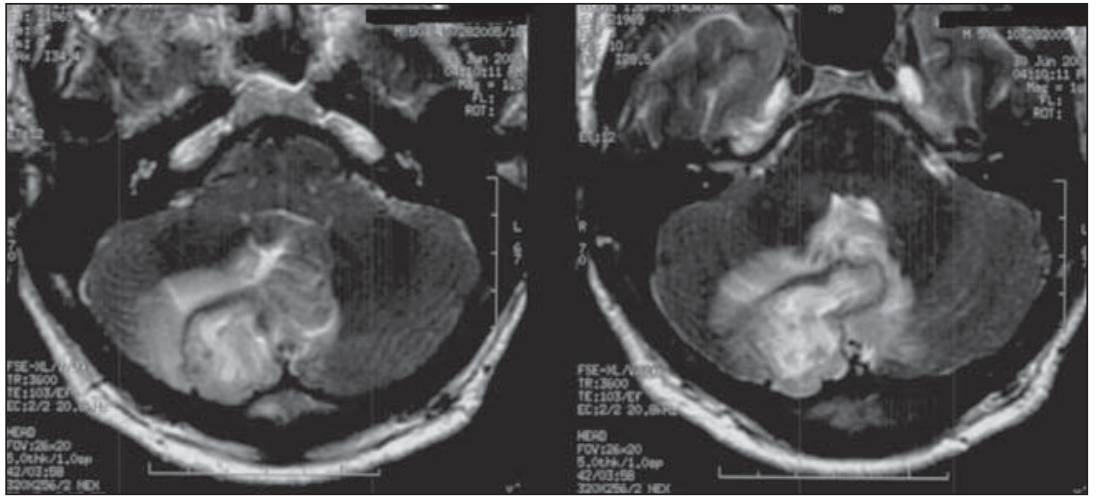

Fig 3. FLAIR sequence showing significant edema involving the lesion. 


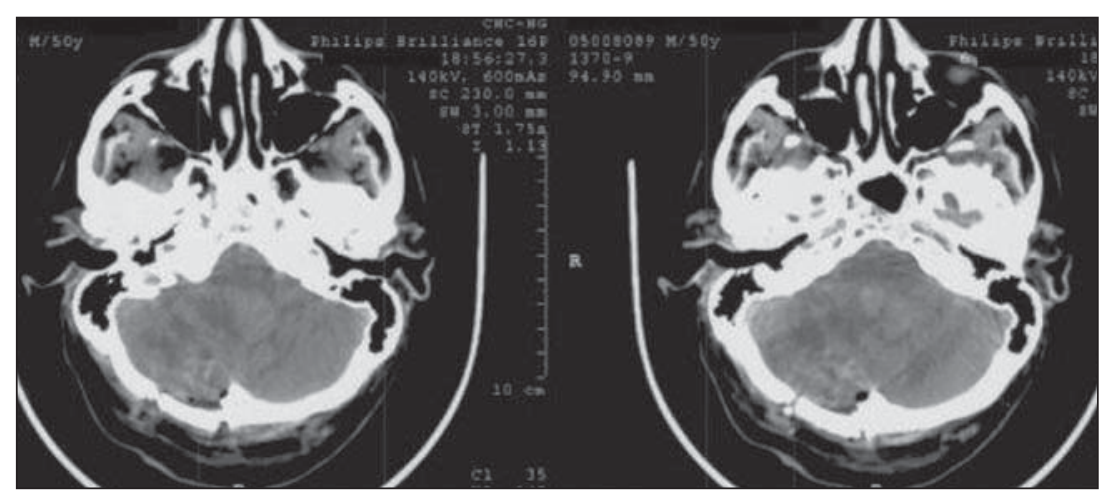

Fig 4. First day post-operative CT scan without surgical complications.
A right sub-occipital craniotomy was performed and drainage of the abscess and removal of its capsule was achieved without intercurrences. Post-operative CT (Fig 4) showed no complications.

Laboratory analysis of the aspirate identified Gemella morbillorum as the pathogen implicated in the infection.

Recovery from surgery was uneventful and a gradual clinical improvement was obtained. Antimicrobial therapy was then modified according to in vitro susceptibility of the Gemella morbillorum, maintaining metronidazole in monotherapy for approximately six weeks.

Six months after surgery the patient was neurologically intact, with CT showing a right cerebellar hemisphere hipodensity.

A trans-esophageal echocardiogram revealing "ostium secundum" inter-auricular communication of 26 millimeters was performed. Pulmonary artery systolic pressure of $35 \mathrm{mmHg}$ was measured by coronary catheterization (moderate pulmonary hypertension).

He subsequently underwent a surgical correction of the inter-atrial septal defect by a median sternotomy using an authologous pericardium patch. In the cardiac follow up the patient presented with no symptoms and had no residual shunt.

The patient gave the informed consent for publish this case.

\section{DISCUSSION}

The most frequent implicated organism in cerebral abscesses is streptococcus and multiple organisms are identified in different percentage according to the series. When resulting from otitis, mastoiditis or lung abscess, anaerobes or multiple organisms are the most common pathogens. Staphylococci are prevalent with penetrating head trauma or following neurosurgical procedures. Fungal infections occur mainly in immunocompromised patients. Cultures from cerebral abscesses don't reveal any bacteria in up to $25 \%$ of cases. Unusual microorganisms are seldom identified. Gemella species, including Gemella morbillorum, a microaerophilic Gram-positive coccus, are part of the normal flora of the human oropharynx, upper respiratory, urogenital and gastrointesti- nal tract rarely causing human infection. Although uncommonly pathogenic, they have been implicated in a variety of human infections, some of them with serious consequences, most notably infective endocarditis $^{1-7}$. Dental instrumentation appears to be the usual source of infection'.

Central nervous system infection is unusual and brain abscess formation due to these bacteria is a rare condition with only four cases previously described ${ }^{8-11}$.

Other infections like bacteremia ${ }^{12}$ septic arthritis ${ }^{13}$, pneumonia ${ }^{14}$, pleural empyema ${ }^{15-18}$, liver abscess ${ }^{19-22}$, spondylodiscitis ${ }^{23}$, septic shock ${ }^{24}$, pericarditis ${ }^{25}$, soft tissue infection ${ }^{26}$, sub-dural empyema ${ }^{27}$ (complication of frontal sinusitis) are also uncommon.

Differentiation of Gemella from viridans streptococci may be difficult: $16 \mathrm{~S}$ rRNA gene sequencing is the method of choice for identification of gemella species ${ }^{28}$.

Although Gemella morbillorum is usually sensitive to beta-lactamics and aminoglycosides, some resistant strains to these antibiotics have been described ${ }^{29}$. Periodontal antimicrobial prophylaxis with tetracycline may result in transitory selection of subgingival species, including Gemella morbillorum, intrinsically resistant to this drug. The percentage of resistant microorganisms increases significantly at one week but falls to baseline levels over time ${ }^{30}$.

Pathogenic mechanisms implicated in Gemella infections include down regulation of IL-12 and IFN- $\gamma$ as well as stimulation of antineutrophil antibodies ${ }^{8}$.

Inter-atrial communication (IAC) accounts for $10 \%$ of all congenital cardiac malformations and results of alterations in inter-auricular septum embriogenesis. IAC ostium secundum has a central location near the fossa ovalis, unlike sinus venosum (close to vena cava) and ostium primum (close to the atrial-ventricular valves). This malformation (ostium secundum), which initially presents with left to right intra-cardiac shunt, results in overload of the right chambers, with 
possible dilation, and pulmonary circulation hypertension, eventually leading to right to left shunt.

Headaches are a common feature (recently described) affecting approximately $30-40 \%$ of patients. Cerebro-vascular embolic accidents may also occur.

In this case, the Gemella bacteria, commensals of the oral cavity, may have entered the blood stream after the dental procedure, and passing through the inter-auricular defect escaped the activity of pulmonary macrophages, reaching the cerebral circulation causing the cerebellar abscess.

Although an uncommon pathogen, Gemella morbillorum has been increasingly associated with serious and potentially life-threatening infections. Diagnostic delays must be avoided to prevent the development of severe consequences.

\section{REFERENCES}

1. FitzGerald SF, Moloney AC, Maurer BJ, Hall WW. Gemella endocarditis: consider the colon. J Heart Valve Dis 2006;15:833-835

2. Gimigliano F, Carletti M, Carducci G, Iodice F, Ballerini L. Gemella morbillorum endocarditis in a child. Pediatr Infect Dis J 2005;24:190.

3. Zakir RM, Al-Dehneh A, Dabu L, Kapila R, Saric M. Mitral bioprosthetic valve endocarditis caused by an unusual microorganism, Gemella morbillorum, in an intravenous drug user. J Clin Microbiol 2004;42:4893-4896.

4. Al Soub H, El-Shafie SS, Al-Khal AL, Salam AM. Gemella morbillorum endocarditis. Saudi Med J 2003;24:1135-1137.

5. Benes J, Picha D, Kabelkova M, Dzupova O, Horova B, Gabrielova A. Infective endocarditis caused by unusual gram-positive pathogens. Folia Microbiol (Praha) 2002;47:737-741.

6. Akiyama K, Taniyasu N, Hirota J, Iba Y, Maisawa K. Recurrent aortic valve endocarditis caused by Gemella morbillorum: report of a case and review of the literature. Jpn Circ J 2001;65:997-1000.

7. La Scola B, Raoult D. Molecular identification of Gemella species from three patients with endocarditis. J Clin Microbiol 1998;36:866-871.

8. Liberto MC, Matera G, Puccio R, et al. An unusual case of brain abscess by Gemella morbillorum. Jpn J Infect Dis 2006;59:126-128.

9. Spagnoli D, Innocenti L, Ranzi ML, Tomei G, Villani RM. Cerebral abscess due to Gemella morbillorum. Eur J Clin Microbiol Infect Dis 2003; 22:515-517.

10. Messori A, Bertolucci F, Dimi M, et al. Gemella morbillorum deep brain abscess successfully treated with combined stereotactic, medical, and imaging approach; Eur J Radiol 2002;44:143-151.
11. Murray CK, Hospenthal DR, Grimberg BT, Gasser RA. Gemella morbillorum brain abcess presenting as acute meningitis. Infect Dis Clin Pract 1998; 7:477-480.

12. Reyes R 3rd, Abay A, Siegel M. Gemella morbillorum bacteremia associated with adenocarcinoma of the cecum. Am J Med 2001;111:164-165.

13. Roche M, Smyth E. A case of septic arthritis due to infection with Gemella morbillorum. J Infect 2005;51:187-189.

14. Signes-Costa J, Chiner E, Arriero JM. Gemella morbillorum necrotizing pneumonia and empyema in a laryngectomized patient. Arch Bronconeumol 2000;36:601-602.

15. Valipour A, Koller H, Setinek U, Burghuber OC. Pleural empyema associated with Gemella morbillorum: report of a case and review of the literature. Scand J Infect Dis 2005;37:378-381.

16. Poulose V. Gemella empyema cured without antibiotics: a case report. Ann Acad Med Singapore 2002;31:802-804.

17. Canet JJ, Hernandez R, Almagro P, Garau J. Pleural empyema due to Gemella morbillorum. Enferm Infecc Microbiol Clin 2001;19:189.

18. Hayashi Y, Ito G; A case of bacterial empyema caused by Gemella morbillorum. Kansenshogaku Zasshi 1996;70:259-263.

19. Nam HJ, Yoon SJ, John BM, et al. Liver abscess caused by Gemella morbillorum. Korean J Gastroenterol 2005;46:56-59.

20. Calvo A, Colodro A, Ladcro M, et al. Liver abscess in Crohn's disease due to Gemella morbillorum. Rev Esp Enferm Dig 2003;95:440-441.

21. Millan Rodriguez AB, Jimenez Saez M, Herrerias Gutierrez JM. An infrequent presentation of Gemella morbillorum infection: liver abscess. Gastroenterol Hepatol 2003;26:396.

22. Perea Garcia J, del Valle Hernandez E, Medina Rodriguez J, Munoz Jimenez F. Liver abscess: a rare manifestation of Gemella morbillorum infection. Med Clin (Barc) 2002;118:239.

23. Eisenberger U, Brunkhorst R, Perharic L, Petersen R, Kliem V. Gemella morbillorum: spondylodiscitis in a patient with a renal graft. Nephrol Dial Transplant 1998;13:1565-1567.

24. Vasishtha S, Isenberg HD, Sood SK. Gemella morbillorum as a cause of septic shock. Clin Infect Dis 1996;22:1084-1086.

25. Condoluci C, Chessa M, Butera G, Cipriani A, Pelargonio S. Pericarditis caused by Gemella morbillorum: description of a case. Minerva Pediatr 1995; 47:545-547.

26. Bachmeyer C, Landgraf N, Daumas L. Soft tissue infection caused by Gemella morbillorum in two intravenous drug users. J Am Acad Dermatol 2005;52:704-705.

27. Martinez Beneito MP, de la Fuente Arjona L, Garcia Callejo FJ, Mallea Canizares I, Blay Galaud L, Marco Algarra J. Subdural empyema of sinus origin caused by Gemella morbillorum, a strange etiology. Acta Otorrinolaringol Esp 2002;53:427-430.

28. Woo PC, Lau SK, Fung AM, Chiu SK, Yung RW, Yuen KY. Gemella bacteraemia characterised by $16 \mathrm{~S}$ ribosomal RNA gene sequencing. J Clin Pathol 2003;56:690-693.

29. Kofteridis DP, Anastasopoulos T, Panagiotakis S, Kontopodis E, Samonis G. Endocarditis caused by Gemella morbillorum resistant to beta-lactams and aminoglycosides. Scand J Infect Dis 2006;38:1125-1127.

30. Rodrigues RM, Goncalves C, Souto R, Feres-Filho EJ, Uzeda M, Colombo AP. Antibiotic resistance profile of the subgingival microbiota following systemic or local tetracycline therapy. J Clin Periodontol 2004;31:420-427. 